\title{
SUBTROPICAL AND POLAR CIRRUS CLOUDS CHARACTERIZED BY GROUND-BASED LIDARS AND CALIPSO/CALIOP OBSERVATIONS
}

\author{
Carmen Córdoba-Jabonero ${ }^{*}$, Fabio J. S. Lopes ${ }^{2}$, Eduardo Landulfo ${ }^{2}$, \\ Héctor Ochoa $^{3}$, Manuel Gil-Ojeda ${ }^{1}$ \\ ${ }^{I}$ Instituto Nacional de Técnica Aeroespacial (INTA), Atmospheric Research and Instrumentation Branch, \\ Torrejón de Ardoz, 28850-Madrid, Spain,*Email: cordobajc@inta.es \\ ${ }^{2}$ Instituto de Pesquisas Energéticas e Nucleares (IPEN), Center for Lasers and Applications, São Paulo, \\ Brazil
}

${ }^{3}$ Instituto Antártico Argentino/Dirección Nacional del Antártico (IAA/DNA), Buenos Aires, Argentina

\begin{abstract}
Cirrus clouds are product of weather processes, and then their occurrence and macrophysical/optical properties can vary significantly over different regions of the world. Lidars can provide height-resolved measurements with a relatively good both vertical and temporal resolutions, making them the most suitable instrumentation for high-cloud observations. The aim of this work is to show the potential of lidar observations on Cirrus clouds detection in combination with a recently proposed methodology to retrieve the Cirrus clouds macrophysical and optical features. In this sense, a few case studies of cirrus clouds observed at both subtropical and polar latitudes are examined and compared to CALIPSO/CALIOP observations. Lidar measurements are carried out in two stations: the Metropolitan city of Sao Paulo (MSP, Brazil, $23.3^{\circ} \mathrm{S} 46.4^{\circ} \mathrm{W}$ ), located at subtropical latitudes, and the Belgrano II base (BEL, Argentina, $78^{\circ} \mathrm{S} 35^{\circ} \mathrm{W}$ ) in the Antarctic continent. Optical (COD-cloud optical depth and LR-Lidar Ratio) and macrophysical (top/base heights and thickness) properties of both the subtropical and polar cirrus clouds are reported. In general, subtropical Cirrus clouds present lower LR values and are found at higher altitudes than those detected at polar latitudes. In general, Cirrus clouds are detected at similar altitudes by CALIOP. However, a poor agreement is achieved in the LR retrieved between ground-based lidars and space-borne CALIOP measurements, likely due to the use of a fixed (or low-variable) LR value in CALIOP inversion procedures.
\end{abstract}

\section{INTRODUCTION}

The influence of Cirrus clouds on weather and climate is actually an evident fact. Indeed, they can act as modulators in the radiation balance of the Earth-atmosphere system, and their heating or cooling effects can be observed at both regional and global scales [1]. However, the sensitivity of Cirrus clouds to factors associated with humaninduced climate changes, i.e. greenhouse effect [2] and contamination of the upper troposphere from increasing aircraft traffic [3], is still poorly investigated. The predominance of infrared greenhouse warming versus solar albedo cooling depends sensitively on both the altitudes and microphysical compositions of the Cirrus clouds [4]. Indeed, cloud height has an evident impact. Hence, high tropical Cirrus can be particularly effective greenhouse modulators. Conversely, lower Cirrus over Polar Regions could be more efficient for albedo effects. Moreover, Cirrus clouds are product of weather processes, and then their occurrence and macrophysical/optical properties can vary significantly over different regions of the world. Since Cirrus clouds usually are located from $7 \mathrm{~km}$ height up to the tropopause, active remote sensing techniques, as lidars, are usually used for detection of Cirrus clouds from ground-based [5] and space [6] observations.

The aim of this work is to show the potential of ground-based lidar observations on Cirrus clouds detection in combination with a recently proposed methodology [7] to retrieve the Cirrus clouds macrophysical and optical features. In this sense, Cirrus clouds observations are performed in particularly located lidar stations at both subtropical and polar latitudes in order to establish a long-term Cirrus clouds monitoring over these 
stations in the future. In this first step, a case study of Cirrus clouds observed over these subtropical and polar stations are presented. Their both macrophysical (vertical extent, top/base heights and thickness), and optical (COD-Cloud Optical Depth, LR-Lidar Ratio=extinction-to-backscatter ratio) properties are reported. A comparative analysis is also performed between ground-based lidar measurements and space-borne CALIPSO/CALIOP (www-calipso.larc.nasa.gov) observations [8]. Similarities and discrepancies are also discussed.

\section{METHODOLOGY}

\subsection{Ground-based lidar measurements}

Cirrus (Ci) clouds were detected over both subtropical and polar stations: a) the Metropolitan city of Sao Paulo station (MSP, Brazil, $23.3^{\circ} \mathrm{S}$ $46.4^{\circ} \mathrm{W}, 740 \mathrm{~m}$ a.s.l.), located at subtropical latitudes and managed by the Instituto de Pesquisas Energéticas e Nucleares (IPEN), and b) the Antarctic Belgrano II base (BEL, Argentina, $78^{\circ} \mathrm{S} 35^{\circ} \mathrm{W}, 256 \mathrm{~m}$ a.s.l.), managed by the Instituto Antártico Argentino (IAA).

A Micropulse Lidar v.4 (MPL-4) is deployed in routine operation at the BEL site; MPL-4 is a standard system of those are within NASA/MPLNET (MicroPulse Lidar NETwork, mplnet.gsfc.nasa.gov), belonging to the Spanish Institute for Aerospace Technology (INTA) in collaboration with the IAA (Argentina). The lidar system operating in the MSP station (SPL system) belongs to the IPEN/Centro de Lasers e Aplicaçoes (IPEN/CLA), and is within LALINET a.k.a. ALINE (Latin America LIdar NETwork, lalinet.org). The main ground-based lidar features are shown in Table 1.

In this work, a case study is presented for each station: Cirrus clouds were detected on 11 June 2007 (early austral winter) over MSP station and on 20 May 2010 (late austral autumn) over BEL site. Both macrophysical and optical properties of the Cirrus clouds observed in those days are retrieved from lidar measurements by using the methodology reported in [7]. Among the macrophysical features, the vertical extent, the top and base heights and the thickness are obtained. The optical properties retrieved, considering also multiple scattering effects, are the Backscattering
Ratio (BSR) profiles, Cloud Optical Depth (COD) and Lidar Ratio (LR, extinction-to-backscatter ratio). In addition, Cirrus layers detected along the day are classified according to their $\operatorname{COD}(\tau)$ into: sub-visual (svCi, $\tau<0.03$ ), semi-transparent (stCi, $\tau: 0.03-0.3$ ), and opaque (opCi, $\tau>0.3$ ). All those parameters were examined for the selected case studies, and compared to CALIPSO/CALIOP Cirrus retrievals.

Table 1. Main information about the two G-B lidar systems and the space-borne CALIOP.

\begin{tabular}{|c|c|c|c|}
\hline Lidar system & SPL & MPL-4 & CALIOP \\
\hline Wavelength $(\mathrm{nm})$ & $532(*)$ & 527 & $532(*)$ \\
\hline $\begin{array}{l}\text { Pulse energy pulse } \\
(\mathrm{mJ})\end{array}$ & $150-330$ & $\begin{array}{l}0.010 \\
(\max .)\end{array}$ & 110 \\
\hline $\begin{array}{l}\text { Pulse repetition } \\
\text { freq. }(\mathrm{Hz})\end{array}$ & $10-20$ & 2500 & 20.25 \\
\hline Eye-safe & No & Yes & No \\
\hline Depolarization & No & Yes & Yes \\
\hline Raman capability & Yes & No & No \\
\hline \multirow[t]{2}{*}{$\begin{array}{l}\text { Acquisition } \\
\text { settings }\end{array}$} & $\begin{array}{l}\text { Vert. } \\
\text { res.: } 3.75 \\
\text { m }\end{array}$ & $\begin{array}{l}\text { Vert. } \\
\text { res.: } 75 \\
\text { m }\end{array}$ & $\begin{array}{c}\text { Vert. res.: } \\
30 \mathrm{~m} \\
(<8.3 \mathrm{~km}), \\
60 \mathrm{~m} \\
(8.3-20.5 \\
\mathrm{km})\end{array}$ \\
\hline & $\begin{array}{l}\text { Int. time: } \\
1-2 \text { min }\end{array}$ & $\begin{array}{l}\text { Int. time: } \\
1 \text { min }\end{array}$ & $\begin{array}{l}\text { Horiz. res.: } \\
\quad 333 \mathrm{~m}\end{array}$ \\
\hline
\end{tabular}

(*) Used in this work.

\subsection{Space-borne CALIOP observations}

CALIOP (Cloud-Aerosol Lidar with Orthogonal Polarization) is a two-wavelength elastic lidar system aboard CALIPSO satellite [8]. Its principal features are shown in Table 1. CALIPSO Level 1 data were analyzed in order to retrieve the total attenuated backscatter product and calculate the BSR profiles for each station. A total of 300 profiles were selected in order to obtain a total horizontal range of $100 \mathrm{~km}$. Each 15 consecutive profiles of the total attenuated backscatter were averaged in order to obtain a BSR with a horizontal resolution of $5 \mathrm{~km}$. Hence, 20 BSR profiles centered in the coordinates of each lidar station were examined. In particular, CALIPSO overpasses were performed at around 17:08 UTC and 01:34 UTC, respectively, over MSP and BEL stations for those selected days; the closest 
distance between the CALIPSO ground-track and MSP and BEL sites was $72.5 \mathrm{~km}$ and $75.3 \mathrm{~km}$, respectively. COD values were obtained from CALIPSO Level 2 Cloud Layer products with 5$\mathrm{km}$ horizontal resolution, being retrieved the number of cloud layers detected and their base and top altitudes, as well as their Cloud-Aerosol Discrimination score (CAD) [9]. COD values were also used to classify the Cirrus clouds, and the LR for each cloud profile was also provided.

\section{RESULTS}

\subsection{Subtropical MSP case}

The evolution of the Cirrus clouds observed over MSP station on 11 June 2007 based on G-B SPL measurements presented a layered structure composed of one or two layers with alternating COD values between stCi and opCi clouds, but no svCi were detected. Figure 1 shows the BSR profiles obtained from SPL (left panel) and CALIOP (right panel) observations as classified depending on the COD. Both stCi and opCi occurrence is found between 8 and $11 \mathrm{~km}$ height, at similar altitudes as those found for CALIOP detected Cirrus clouds. In addition, G-B retrieved LR values are higher for stCi (20-30 sr) than for opCi (10-20 sr) clouds. However, a fixed value of $25 \mathrm{sr}$ is used in CALIOP LR retrievals independently on the Ci-type category.

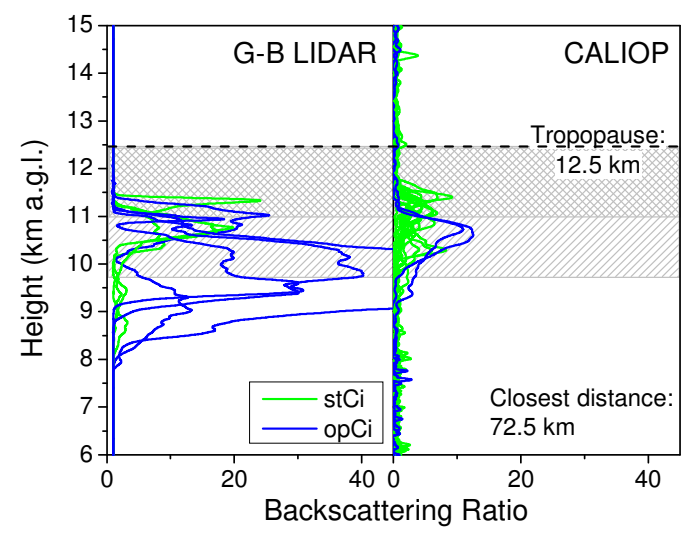

Fig. 1. BSR profiles for the subtropical Cirrus clouds observed over MSP station on 11 June 2007 depending on COD (svCi: red lines, stCi: green lines, and opCi: blue lines) obtained from SPL (left) and CALIOP (right) measurements.

\subsection{Polar BEL case}

In this case, opCi are observed over BEL station on 20 May 2010 based on G-B MPL-4 measurements for the first two hours, followed by svCi and stCi (CODs for these stCi are close to 0.08 , values nearly within svCi category). Cirrus persist at similar heights along the day (unfortunately, no data available from 16:00 UTC on). Figure 2 shows the BSR profiles obtained from MPL-4 (left panel) and CALIOP (right panel) observations as classified depending on the COD. In general, polar Cirrus are found at lower altitudes than those for the subtropical case, as expected at polar latitudes. Cirrus clouds detected by CALIOP are only within opCi category, but their altitudes are coincident with those observed by G-B lidars. In addition, LR values derived from MPL-4 measurements are between 15 and $30 \mathrm{sr}$ for $\mathrm{svCi}$, and $30 \mathrm{sr}$ for both stCi and opCi clouds. These LR values are dissimilar in comparison to those obtained for the Ci-type categories found in the subtropical case. In addition, CALIOP-retrieved LR are slightly variable $(22 \pm 2 \mathrm{sr})$ for the only opCi clouds detected, being values relatively lower than those derived by G-B lidar measurements for these opCi clouds.

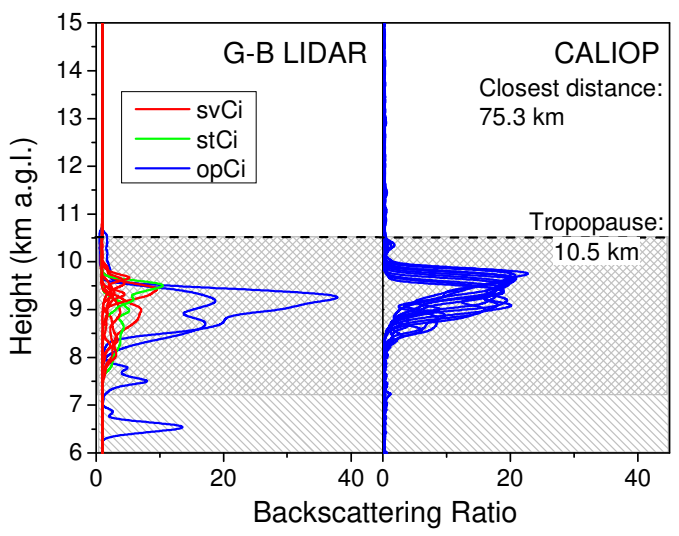

Fig. 2. The same as for Fig. 1, but for the polar Cirrus clouds observed over BEL station on 20 May 2010 obtained from MPL-4 (left) and CALIOP (right) measurements.

\section{CONCLUSIONS}

Cirrus clouds have been analyzed in terms of their macrophysical and optical properties as retrieved 
by a recently developed methodology applied to lidar measurements. A case study of Cirrus clouds observed at both subtropical and polar latitudes are presented in this work. These cases correspond to the Cirrus detected over the subtropical MSP station and the Antarctic BEL base. Their BSR profiles together with their altitude levels, COD and LR values have been reported. This study has been focused on the classification of the daily cloud features into three Ci-type categories related to their $\mathrm{COD}(\tau)$ : svCi $(\tau<0.03)$, stCi $(\tau:$ : 0.03-0.3), and opCi $(\tau>0.3)$.

Based on G-B lidar measurements, subtropical svCi and opCi clouds present LR values lower than $10 \mathrm{sr}$ and $10-20 \mathrm{sr}$, respectively, while they are higher for polar Cirrus clouds (svCi: $15-30 \mathrm{sr}$, and opCi: $30 \mathrm{sr}$ ). However, svCi were not detected by CALIOP, and a larger fixed ( $25 \mathrm{sr}$ ) and a smaller low-variable $(22 \pm 2 \mathrm{sr}) \mathrm{LR}$ values were derived/used for subtropical and polar opCi clouds, respectively. stCi clouds represent a mixed state of those svCi and opCi clouds. Regarding their altitudes, subtropical svCi were located higher than opCi clouds (from $10 \mathrm{~km}$ and $8 \mathrm{~km}$ height, respectively, up to tropopause heightlevels). Polar Cirrus were observed, in general, at lower altitudes, as expected in Polar Regions. For comparison, Ci clouds were detected by CALIOP at similar altitudes. It should be noted that these results are specific for those study cases analyzed. However, in general, subtropical Cirrus clouds present lower LR values and are found at higher altitudes than those $\mathrm{Ci}$ detected at polar latitudes. Similarities and differences can be plausibly found, as long as a larger dataset can be available to be analyzed in each station.

These results can be into consideration to improve the treatment of the different latitude-types of Cirrus clouds to be introduced in large-scale models for climate-related issues, as well as to be useful in validation assessments of the retrieval of their properties from future satellites (i.e., next ESA/EarthCARE and Sentinels missions).

\section{ACKNOWLEDGEMENTS}

This work has been supported by the Spanish Ministerio de Economía y Competitividad (MINECO, grant CGL2011-24891) and the Brazilian Fundação de Amparo à Pesquisa do Estado de São Paulo (FAPESP, grant 2011/14365-
5). C. C.-J. also thanks FAPESP for their support (grant 2013/11836-2) during her research stay in the Instituto de Pesquisas Energéticas e Nucleares (IPEN, Brazil). Authors are grateful to the staff of all the stations responsible for instrumentation maintenance and support.

\section{REFERENCES}

[1] Liou, 1986: Influence of cirrus clouds on weather and climate processes: A global perspective, Mon. Weather Rev. 114, 1167-1200.

[2] Iacono et al., 2008: Radiative forcing by longlived greenhouse gases: Calculations with the AER radiative transfer models, J. Geophys. Res. Atmos. 113, D13103.

[3] Boucher, 1999: Air traffic may increase cirrus cloudiness, Nature 397, 30-31.

[4] Myhre et al., 2013: Anthropogenic and Natural Radiative Forcing. In: Climate Change 2013: The Physical Science Basis. Contribution of Working Group I to the Fifth Assessment Report of the Intergovernmental Panel on Climate Change [Stocker, T.F., D. Qin, G.-K. Plattner, M. Tignor, S.K. Allen, J. Boschung, A. Nauels, Y. Xia, V. Bex and P.M. Midgley (eds.)]. Cambridge University Press, Cambridge, United Kingdom and New York, NY, USA.

[5] Sassen and Campbell, 2001: A midlatitude cirrus cloud climatology from the Facility for Atmospheric Remote Sensing. Part I: Macrophysical and synoptic properties, J. Atmos. Sci. 58, 481-496.

[6] Sassen et al., 2008: Global distribution of cirrus clouds from CloudSat/Cloud-Aerosol Lidar and Infrared Pathfinder Satellite Observations (CALIPSO) measurements, J. Geophys. Res. 113, D00A12, doi:10.1029/2008JD009972.

[7] Larroza et al., 2013: Towards an automatic lidar cirrus cloud retrieval for climate studies, Atmos. Meas. Tech. 6, 3197-3210.

[8] Winker et al., 2009: Overview of the CALIPSO mission and CALIOP data processing algorithms, J. Atmos. Ocean. Tech. 26, 23102323.

[9] Liu et al., 2009: The CALIPSO Lidar cloud and aerosol discrimination: Version 2 algorithm and initial assessment of performance, J. Atmos. Ocean. Tech. 26, 1198-1213. 